\title{
Meaning of Family-Professional Partnerships: Japanese Mothers' Perspectives
}

MAHO KASAHARA

Syracuse University

ANN P. TURNBULL

University of Kansas

AвSTRACT: This study inquired into the meaning of family-professional partnerships from the perspective of Japanese families of children with disabilities. Data were collected from 30 mothers who participated in focus groups and/or interviews in Japan. Qualitative data analysis guided identification of four themes. The study's contributions are discussed in relation to not only Japanese society, but also to the global community including the United States. The study's implications for developing partnerships with culturally diverse families also are discussed.

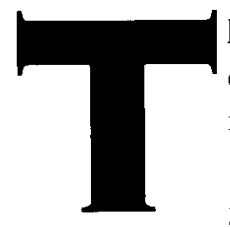

he current trend in Japanese special education and social welfare fields is best characterized as a transition to the new era. Japanese governmental departments that oversee these two fields have published reports announcing their policy reform frameworks and restructuring plans (Ministry of Education, Culture, Sport, Science, \& Technology Japan, 2001, 2003; Ministry of Health, Labour, \& Welfare of Japan, 1998). The special education field (as well as other disciplines) in the United States has also undergone a significant paradigm shift that involves rethinking ways to deliver services and work with families of children with disabilities. Special education and social welfare fields in the United States have embraced the concept of family-centered practice that values family choice and believes in the family's inherent strengths and ca- pabilities (Allen \& Petr, 1996). These disciplines have also embraced the concept of family-professional partnerships, which values equality (Allen $\&$ Petr; Blue-Banning, Summers, Frankland, Nelson, \& Beegle, 2004; Cunningham \& Davis, 1985; DeChillo, Koren, \& Schultze, 1994; Turnbull, Turbiville, \& Turnbull, 2000), interdependence (Bond \& Keys, 1993; Cunningham \& Davis; Turnbull \& Turnbull, 2001); and joint decision making as well as mutual benefit (Dunst $\&$ Paget, 1991; Turnbull \& Turnbull).

Close examination of the Japanese government's restructuring plans reveals two emerging needs regarding family-centered philosophy and family-professional partnerships. First, little consensus exists between special education and social welfare about how the family is considered within their policy and service-provision frameworks. In a report that describes a new frame- 
work within the Japanese special education field, families are barely visible (see Ministry of Education, Culture, Sport, Science, \& Technology Japan, 2001, 2003). The report lacks the perspective of family support and involvement and sees the decision-making power of families as subordinate to that of professionals. In contrast, the Japanese social welfare field has adopted a perspective similar to the family-centered philosophy in the United States that attends to the whole family as a unit to be supported (Nakano et al., 1998). It has also adopted the principle of consumerism and gives consumers power to choose services (Ministry of Health, Labour, \& Welfare of Japan, 1998). This lack of consensus between special education and social welfare will likely confuse families who interact with both worlds.

\section{Special education and social welfare fields in the United States have embraced the concept of family-centered practice that values family choice and believes in the family's inherent strengths and capabilities.}

The second need addresses working relationships between families and professionals. Although the report on the social welfare restructuring plan addresses "equal relationships between people who provide services and who receive them" (Ministry of Health, Labour, \& Welfare of Japan, 1998), as one of its seven goals, no further discussion occurs on what "equal relationships" mean and what is needed to establish them. Additionally, there is a void of researchbased information and knowledge to foster such discussions. The absence of research and discussions on desirable family-professional partnerships is even more significant in special education in the new framework report, which lacks any attention to this issue. A literature search of several major Japanese research databases confirmed the significant shortage of research related to partnerships between families of individuals with disabilities and professionals. In spite of such low attention from policymakers and researchers, family-professional partnerships are considered an important factor in the context of service delivery and often become the focus of informal discussions among people involved in the partnerships (e.g., Kodama, 1998). Moreover, considering that services and political actions ultimately will be carried out through human relationships, the need to strengthen research-based knowledge and discussions related to this issue should be a priority.

Adopting family systems theory (Turnbull \& Turnbull, 2001) and ecological theory (Bronfenbrenner, 1979) as a theoretical basis, this study considers the family an important stakeholder who significantly influences the child's development, which, in turn, affects each family's unique operation. Embracing such a view, the primary purpose of this study was to qualitatively inquire, from the perspectives of families, into the meaning of desirable partnerships between families of young children with disabilities and professionals who serve those children in Japan. Thus, this study's primary research question is: What does it mean for the family of a child with disabilities in Japan to have a good relationship - a desirable partnership - with professionals who serve their child? Additionally, as a long-term outcome, it was anticipated that such an inquiry would also have implications for practices in the United States for developing family-professional partnerships with culturally diverse families.

\section{METHOD}

\section{PARTICIPANTS}

In order to maximize the scope and range of information obtained (Lincoln \& Guba, 1985), three sites were selected. These sites reflected varied patterns and availability of special education and other disability-related services and systems, and different geographical characteristics (i.e., Site $\mathrm{Y}$ is the second largest city in Japan adjacent to metropolitan Tokyo, Site $\mathrm{M}$ is a growing commuter town close to a metropolitan area, and Site $F$ is in the northern part of Japan where isolation and informational lag are more common than in the other two sites). The focus of this study was not, however, to identify site-specific differences. Rather, it concerned patterns cutting across three 
sites to derive a generic understanding of the meaning of desirable family-professional partnerships from the perspectives of families in Japan. Future research may examine such site-specific differences.

Following the "purposive sampling" (Lincoln \& Guba, 1985, p. 199) plan of qualitative inquiry as well as the "snowball sampling" (Lincoln \& Guba, 1985, p. 233) strategy, participants were recruited through several mediators. These mediators were parents presumed to have strong contacts with other families. This presumption was based on the first author's experiences of either having known them personally or having found them identified as leaders in parental organizations listed on an Internet search. Through these mediators, information packets that contained details about the study were distributed to potential participants. Criteria for recruiting participants included (a) being a family member of a young child (birth to approximately 12 years of age) with a disability, (b) interacting with professionals frequently, and (c) living in one of three targeted sites. Thirty mothers ( 8 from Site $Y, 10$ from Sire $M$, and 12 from Site F) participated. Although the study did not intentionally exclude fathers and other extended family members, the recruitment criteria resulted in all participants being mothers. Tables 1 and 2 summarize demographic information of participants and their children with disabilities.

\section{DATA COLLECTION}

Data were collected through focus groups/interviews, member checking, and follow-up contacts. First, focus groups (Brotherson, 1994; Krueger \& Casey, 2000) were held at each of three targeted sites in the summer of 2001 and included 28 participants ( 8 at Site $Y$ focus group, 8 at Site $M$, and 12 at Site F). The remaining 2 participants out of the 30 mothers, both from Site $M$, could not attend a focus group because of schedule conflicts. Interviews with the 2 participants who could not attend were arranged and conducted using a procedure similar to the focus group so they could participate in the study. Each focus group and interview lasted about 2 hours. The first author served as a discussion facilitator. Each meeting was comprised of three phases: warm-up, discussion, and conclusion. A Focus Group Guide that outlined each phase and basic procedure was developed in advance and was based on related literature (e.g., Park \& Turnbull, 2001; Skrtic, 1985). (The Focus Group Guide is available from the first author on request.)

During the initial warm-up phase, the participants briefly introduced themselves. The senior author, who served as a facilitator, reminded participants of the meeting's primary purpose. At the first focus group (Site Y), time was spent discussing the definition of a "professional"; it was decided that professional would refer to those using their expertise who had interacted with participants and/or their children with disabilities. This broad definition of a professional carried over during subsequent focus groups and interviews. Examples of professionals mentioned in discussions ranged from doctors and special education teachers to piano teachers and public officers at a city hall. A majority of participants, however, focused on professionals in education; more than half the focus group participants indicated in written feedback that they thought primarily of teachers. The proportion was even greater when it included professionals who provided developmental/educational therapies or intervention at specialized institutions other than schools.

What does it mean for the family of a child with disabilities in Japan to have a good relationship-a desirable partnership-with professionals who serve their child?

After the warm-up, the discussion phase started by identifying issues to be discussed. Participants reviewed a Preparation Guide, mailed a week prior to the scheduled meetings to help them prepare their thoughts for the meeting. The Preparation Guide did not prescribe specific questions but, rather, listed four broad aspects of the lives of children with disabilities and of their families (i.e., development and education, family life, community life, and advocacy), in which opportunities for family-professional partnerships 
TABLE 1

Summary of Participants' Demographic Information

\begin{tabular}{|c|c|c|c|}
\hline Demographics & Site $Y$ & Site $M$ & Site $F$ \\
\hline \multicolumn{4}{|l|}{ Age } \\
\hline $31-35$ & 0 & 3 & 0 \\
\hline $36-40$ & 4 & 4 & 5 \\
\hline $41-45$ & 3 & 2 & 5 \\
\hline $46-50$ & 1 & 1 & 2 \\
\hline \multicolumn{4}{|l|}{ Work status } \\
\hline Working & 2 & 2 & 5 \\
\hline Nonworking & 6 & 8 & 7 \\
\hline \multicolumn{4}{|l|}{ Year of receiving services } \\
\hline $0-3$ & 0 & 0 & 3 \\
\hline $3-6$ & 4 & 10 & 3 \\
\hline $6-9$ & 4 & 0 & 6 \\
\hline \multicolumn{4}{|l|}{ Level of family needs ${ }^{2}$} \\
\hline Economic & 3.0 & 3.1 & 3.0 \\
\hline Medical \& health & 3.1 & 3.5 & 3.5 \\
\hline Social welfare & 3.9 & 3.9 & 3.9 \\
\hline \multicolumn{4}{|l|}{ Affiliation $^{\mathrm{b}}$} \\
\hline Disability-related & $7(87.5 \%)$ & $4(40 \%)$ & $12(100 \%)$ \\
\hline Community-related & $3(37.5 \%)$ & $3(30 \%)$ & $4(33.3 \%)$ \\
\hline Religious organization & $1(12.5 \%)$ & $1(10 \%)$ & $1(8.3 \%)$ \\
\hline Other or none & $1(12.5 \%)$ & $1(10 \%)$ & $2(16.7 \%)$ \\
\hline
\end{tabular}

Note. Figures show number of participants otherwise indicated.

${ }^{2}$ Self-evaluation responses by participants using 5-point Likert Scale with 5 being the highest need. ${ }^{b} \mathrm{Multiple}$ responses po Percentage indicates ratio to the total number of participants of each site.

could arise (Turnbull \& Turnbull, 2001). The Preparation Guide asked the participants to consider what they would like to discuss within each of the four aspects, especially in relation to interacting with professionals and maintaining desirable working relationships with them. The rationale for this preparation was our belief that issues for discussion should emerge primarily from the participants. Specifically, the researchers did not know what precise probe questions should be asked to answer the research question (Skrtic, 1985). Nor did they know what kinds of contexts or aspects of human relationships were important for the participants in order to understand and define the meaning of family-professional partnerships. As Bogdan and Biklen (2003) stated, in a qualitative study, a researcher needs to use part of the study "to learn what the important questions are" (p. 6).

After the second focus group, the Preparation Guide was modified (Miles \& Huberman, 1994) for the last focus group at Site F. By identifying recurring themes raised by the participants in previous discussions, the researchers gained a better sense of issues and dimensions to be further explored to understand the meaning of partnerships. This procedure was consistent with the iterative "flow of naturalistic inquiry" (Lincoln \& Guba, 1985, p. 188) and with the flexible design of qualitative study, in which "plans formulated as hunches, only to be modified and remolded as... [researchers] proceed" (Bogdan \& Biklen, 2003, 
TABLE 2

Demographic Information of the Participants' Children With Disabilities

\begin{tabular}{|c|c|c|c|}
\hline Demographics & Site $Y$ & Site $\mathrm{M}$ & Sire $\mathrm{F}$ \\
\hline \multicolumn{4}{|l|}{ Age } \\
\hline $3-5$ & 0 & 1 & 3 \\
\hline 6.8 & 7 & 7 & 3 \\
\hline $9-13$ & 1 & 2 & 6 \\
\hline \multicolumn{4}{|l|}{ Primary disability } \\
\hline Physical disability & 7 & 1 & 2 \\
\hline Down syndrome & 0 & 0 & 7 \\
\hline Autism & 0 & 5 & 2 \\
\hline Other & 1 & 4 & 1 \\
\hline \multicolumn{4}{|l|}{ Level of needs" } \\
\hline Mild & 0 & 0 & 2 \\
\hline Moderare & 1 & 5 & 3 \\
\hline Severe/very severe & 6 & 4 & 5 \\
\hline Don't know & 1 & 1 & 2 \\
\hline \multicolumn{4}{|l|}{ Education placement } \\
\hline Regular preschool & 0 & 1 & 2 \\
\hline Regular elementary school & 4 & 6 & 4 \\
\hline Special elementary school & 4 & 3 & 5 \\
\hline Other & 0 & 0 & 1 \\
\hline
\end{tabular}

${ }^{2}$ Self-evaluation by participants.

p. 50). Moreover, it was also consistent with the recursive process of focus group interviewing, which involves constant reflective activity to refine research design, procedures, and questions based on simultaneous data analysis and emerging themes (Brotherson, 1994).

Reflecting themes that emerged from the first two focus groups and interviews (e.g., teaching/interacting with a child, communication, respect, system change needs), the modified Preparation Guide listed the following five questions: (a) How do you want professionals to interact with your child while they provide direct services to your child? (b) What does "good communication with a professional" look and sound like to you? (c) What does "respect" mean to you in the context of interacting with professionals? (d) What is the nature of relationships you hope to develop with professionals (e.g., business-like, friend-like, professional relationships, etc.)? and (e) What do you expect of professionals in relation to your needs for system/service change? (Both initial and modified versions of the Preparation Guide can be obtained from the first author.)

The last phase of the focus group/interviews included activities such as reviewing and summarizing the discussion, as well as requesting any final thoughts to add to emphasize discussion topics. In addition, focus group participants were asked to complete a feedback sheet and to rate, on a 5-point Likert scale with 5 being the highest evaluation, the degree to which they felt comfortable participating in the discussion (comfortable- 
ness evaluation) and the degree to which they felt they could express their thoughts (performance evaluation). The average rating across the three focus groups for the comfortableness evaluation was 4.5, indicating that on average, participants felt "comfortable" (Level 4) or "very comfortable" (Level 5) during the discussions. The average rating for the performance evaluation was 3.8, generally indicating that participants felt they "could share their thoughts" (Level 4) during the discussions. Participants were also invited to provide written comments related to the discussion on the feedback sheet. With advance permission from participants, each focus group session was recorded using both a video and an audio recorder. Interviews were also recorded with an audio recorder.

The second avenue to collect data was a member-checking procedure (Lincoln \& Guba, 1985). This involved sending a preliminary report on the initial data analysis to 20 participants who volunteered as member-checkers. Twelve participants returned the 6-page feedback sheets, which invited their open-ended comments on any of 44 subthemes under the initial 7 themes. They were encouraged to choose and respond to any items they wished without worrying about leaving others blank. There was also a space for free writing at the end. All these comprehensive agreeing/disagreeing comments, clarifications, and elaborations on the initial findings provided by the member-checkers were added to the data pool.

Additional data were collected through an ongoing follow-up process. If a clarification was needed (either oral or written), follow-up occurred via phone or e-mail. The narrative data pool was constructed by combining verbatim transcripts of focus groups/interviews/follow-up and all participants' comments that were provided in a written format (i.e., focus group feedback sheets, member-checker feedback sheets, and email text). This accounted for about 160 pages of double-spaced Japanese text.

\section{DATA ANALYSIS}

A constant comparative method of qualitative analysis (Lincoln \& Guba, 1985), which involved unitizing, categorizing, interpreting and synthesizing data, was used for data analysis. First, transcripts were read carefully in order to identify each minimum unit. A unit was defined as the smallest piece of a participant's comment that could stand by itself and that contained information that was in any sense related to the study's research question (Lincoln \& Guba; Skrtic, 1985). The length of a unit varied from a short, single sentence to a long paragraph (e.g., a paragraph explaining a certain situation illustrating a specific point a participant made). The nearly 600 units were each assigned consecutive numbers and were coded to make tracking back to its data source possible (Skrtic).

Following unitizing, the categorization process began. Each unit was read, was compared with previously read units, and was placed into a new or previously created category based on its "look/feel-alike" quality (Lincoln \& Guba, 1985, p. 347). Upon determining the appropriate category, a unit was frequently referred back to the transcript and interpreted within context of the discussion in which the unit was produced. This step was helpful in grasping subtle nuances of each unit that might be neglected if detached from the flow of a discussion; thus, it increased accuracy of categorization. Upon entering units into categories, a brief rationale of their placement was noted so that the rationale could be examined later. As more units were categorized (categories held a substantial number of units, i.e., six to eight), core properties that the units in a category shared were delineated as a rule of classification (Lincoln \& Guba; Skrtic, 1985). After the first round of categorization was completed, a set of produced categories was reviewed and modified in its entirety. This was accomplished by clarifying and revising category definitions and by justifying each unit in a specific category based on the improved definitions (Lincoln \& $\mathrm{Guba}$ ).

In the interpretation and synthesis stage of data analysis, we examined possible interrelations among the categories that emerged. Those that appeared to share the same underlying theme were combined into one. As described in the previous Data Collection section of this article, the synthesized data and emergent themes were reported as preliminary findings to the 20 membercheckers. Twelve of them commented on the initial data interpretation. In addition to general comments, they also suggested reorganizing themes, rethinking wordings, and varying per- 
spectives on the initially identified themes. Their feedback was then incorporated into the data pool and guided the revision of initially identified themes.

\section{TRUSTWORTHINESS}

Triangulation and member-checking techniques (Lincoln \& Guba, 1985) were used to enhance the study's credibility. (For a description of member-checking, see previous Data Analysis section.) Each category was triangulated by confirming that data were collected from different participants and study sites, as well as through different methods (i.e., focus group/interview, memberchecking, follow-up contacts via phone or e-mail). In addition, an external Japanese researcher conducted an audit trail (Lincoln \& Guba; Skrtic, 1985) to assess both confirmability (the degree to which the assertions were grounded in the data), and dependability (the degree to which the research procedures were consistent and valid). The audit trail took place in a 1-day session in which the auditor examined a variety of materials based on the six Halpern audit trail categories (i.e., raw data, data reduction and analysis, data reconstruction and synthesis, process notes, intentions and disposition, and instrument development; Lincoln \& Guba). The first author was present during the audit trail and answered the auditor's questions regarding the study's overall research procedures. The auditor concluded in his audit report that the study established sufficient degrees of dependability and confirmability.

\section{FIN DINGS}

Four themes that represented participants' preferences and expectations for family-professional partnerships emerged. These themes included (a) quality of child-professional relationship, (b) meaning of professional services and care, (c) principles of family-professional interactions, and (d) family priorities for empowerment and guidance.

\section{THEME 1: QUALITY OF CHILD- PROFESSIONAL RELATIONSHIP}

How professionals perceive and treat children with disabilities was often discussed in relation to the quality of services and the establishment of family-professional partnerships. The quality of a child-professional relationship could be further categorized into the following four subthemes: (a) respect, (b) fight against negative/segregative views of disability, (c) importance of contexts in understanding the child, and (d) principles of high-quality services.

Respect. The notion of respect was fundamental in the quality of child-professional relationships desired by participants. Four aspects of respect were particularly important. The first was respect for a child as an individual human being with dignity: Participants wanted professionals to treat their child as a person entitled to basic human rights and not a case, an object, or a number to study, process, or categorize. One participant, whose child has medically vulnerable conditions, addressed the notion of respect by emphasizing that professionals must recognize and take seriously the irreplaceable value of each child's life.

Second, some participants emphasized that children are active learners with their own wills. They expected professionals to understand and respect children's intentions by sharing the children's perspectives and keeping an open mind, rather than applying and imposing their preconceptions on children's performances.

The third aspect of respect was the professionals' genuine care for children, commitment to do their best for children, and joy in working with children. Many participants had encountered professionals who exhibited or lacked such qualities, and wanted to work with those professionals whose work is deeply rooted in love and respect for children. One participant provided a positive example of a teacher from a developmental center for preschool-age children with disabilities, whose sincere commitment to students' well being was evident to her. The mother said the teacher went beyond her expected duties and made persistent efforts to improve the situations of former students who attended a general elementary school with significant barriers and problems.

Finally, participants appreciated professionals who not only had respect for individual children, but who also promoted respectful acceptance of the child by other children. One 


\section{The notion of respect was fundamental in the quality of child-professional relation- ships desired by participants.}

participant said, "I would know that a teacher really cares about my son if she or he creates a space for him to belong and a meaningful role for him to take in the classroom with typically developing children."

Fight Against Negative/Segregative Views of Disability. Many participants shared experiences of encountering negative views toward their children with disabilities and toward themselves, such as "I feel sorry for you" and "You must be unhappy and hopeless." In addition, one of the participating mothers who works as a school counselor noted the tendency among Japanese people to see individuals with disabilities not only negatively but also as "abnormal." According to her, disabilities were perceived as deviant and unacceptable, and therefore as something that needed to be fixed.

Participants repeatedly called for fundamental change to alter such negative views and assumptions about individuals with disabilities and their families as well as segregative approaches that were often pressed based on negative views of disability. Although many tried to reject the imposed negativity by simply saying, "Don't feel sorry for us!" or "We are NOT unhappy!" only a few participants presented an alternative perspective based more on a normal, holistic view of disability. One mother, for example, regarded her beloved son's disabilities simply as one part of who he is. She noted:

If I had power to reverse the time and were to start all over again, I would still want to have my son as my baby, my son with very severe disabilities just the way he is right now, not him without disabilities. I just love him so much as he is.

Some spoke of the inclusive education approach as a vehicle for changing societal attitudes toward disabilities. They believed that the opportunities to share lives beyond the societal boundary of "disability" would help people appreciate and accept individual differences and diversity. No participant expressed preference for segregation over inclusion in schooling. However, participants varied in their thinking concerning the ways that inclusive educational practices should be implemented. Some participants suggested that all special schools be abandoned, altering the system so that inclusive schools become the only option for all children. Meanwhile, other participants hoped to see implementation of inclusive practices, with attendance at a separate special school available as an option.

Importance of Contexts in Understanding the Child. Participants discussed two kinds of contexts as essential in understanding and supporting children. The first context was the child's developmental history. One participant (mother), a former elementary schoolteacher, pointed out that schoolteachers don't always know a child's developmental history and past experiences, such as developmental goals that the child and family had worked on and achieved, teaching strategies people came up with and tried, and various struggles and successes they experienced in relation to the efforts of enhancing the child's development. According to her, a teacher's lack of knowledge of children's past experiences creates a significant and inevitable gap between how parents and teachers perceive children.

Second, participants addressed the importance of locating a child in the context of family and community life. They described the complex interrelationships between the child, the family, and other environmental factors, as well as needs that could be appreciated only when one understood a child within broader and multiple contexts. For example, one mother talked about how lack of a place for her a child with a disability to safely spend after-school time was keeping her from working. Another participant expressed her need for assistance to visit a hospital where lengthy waiting was anticipated. She described how lengthy waiting periods at hospitals often caused her son to demonstrate socially inappropriate behaviors, leading others to evaluate her son negatively. In turn, those negative evaluations resulted in her feeling shame and a desire for help in handling the situation better.

Principles of High-Quality Services. A signifi- 
cant proportion of participants' comments addressed qualities of educational/developmental services they wanted for their children. One key word for services to be considered high quality was "individualization" based on the unique characteristics of each child, such as developmental stage, strengths, needs, preferences, and previous accomplishments. Some participants emphasized the need for professionals to be flexible and to incorporate appropriate accommodations into their services to provide genuinely individualized and customized services. Another key term for highquality service was "developmental appropriateness" and its ability to motivate children to engage. Many participants said they wanted professionals to come down to a child's eye-level and motivate children through playful activities.

Several participants also said that services provided directly to children should be relevant and as embedded in the child's daily life as possible. These comments suggested that professionals tend to define special education, therapy, and interventions narrowly as special kinds of activities, special settings outside of daily lives, and special skills without considering their relevance to the child's actual life. For example, one participant shared her frustrating experience with her son's teacher at a special school, who rejected her request to incorporate some of her son's motor-related developmental objectives into swimming activities at the school during summer. The rejection was based on the premise that swimming was not for "training" but just for "play."

Finally, half the participants emphasized that professionals must possess and base their services on sound disability-related knowledge and skills. Many worried that professionals who interacted directly with their children might do harm because of insufficient knowledge and skills to handle specific disabilities. These comments also indicated that such concerns substantially influenced their decisions about services, such as whether to place their child in an inclusive school or to participate in a community after-school program.

\section{THEME 2: MEANING OF PROFESSIONAL}

SERVICES AND CARE

How professionals perceive the services and care they provide for children with disabilities and their families also was an important factor influencing the nature of family-professional relationships. Participants' views were expressed in two subthemes: (a) emerging concept of service and (b) principle of needs-driven.

Emerging Concept of Service. Several participants expressed comfort using the term service to refer to support obtained from professionals, whereas a few were uncomfortable with this term. One participant said the term service gave her a dehumanizing and artificial impression, making professional care for children and families sound like mere business or an obligation. To its proponents, however, service emphasized consumers' rights to obtain and benefit from services. This rights perspective lessened the sense of guilt families often felt for asking society a "favor." One participant who strongly advocated the concept of service said it also implied that professionals were provided necessary resources to fulfill their official responsibilities in supporting the lives of children with disabilities and their families.

Principle of Needs-Driven. Whether they used the word service or not, participants agreed that services should be needs-driven. Many participants expressed frustration about services constrained by rules that were unresponsive to consumers' needs. They said that actual needs of children and families should determine services, if they were to be effective. Some comments addressed inflexible attitudes among teachers. For example, one participant shared her experience of being told by a teacher not to expect any specialized services (e.g., speech therapy and physical therapy) at the school, because "only people called 'teachers' work at school."

Professionals who listen to and respect families' needs were central to needs-driven services. In addition, participants emphasized the importance of multiple options for families if services are truly needs-driven. For example, one participant said, "I'd like to be able to try and experience a couple of different options, then choose what is best for my child instead of being forced to make only one final choice."

THEME 3: PRINCIPLES OF FAMILY-PROFESSIONAL INTERACTIONS

Participants' comments addressing desired principles for reciprocal interactions between the family 
and a professional were categorized into the following three subthemes: (a) nonhierarchy, (b) interdependence, and (c) empathy, commitment, and trustworthiness.

Nonbierarchy. Many participants perceived a common tendency for professionals to consider themselves as people of higher status than families seeking their help. They also expressed a desire to equalize family-professional relationships. Equal relationship meant being respected as a collaborator with valuable perspectives. Moreover, one participant said she would like professionals to realize that all people (no matter if one is called "professional" or "mother" or has a disability or not) are born with different roles and should regard each other as equally valuable, contributing human beings. Another participant who repeatedly expressed a desire to work with a committed professional based on a human-to-human relationship voiced a similar view. No participants' comments expressed disagreement with equal relationships or preferred hierarchical family-professional relationships.

Interdependence. Many participants said they wanted to feel supported, that "I'm not alone." They expected professionals to be their reliable allies with whom they could share goals, frustrations, resources, responsibilities, tasks, and celebrations. Some specifically pointed out the lack of support when their children were initially diagnosed. Looking back on their own early experiences in which doctors provided no helpful follow-up or emotional assurance, they suggested that the strong sense of reliable allies should be promoted and conveyed from the beginning.

One distinctive issue related to interdependence addressed the decision-making process. Many participants indicated they preferred collaborative decision making. They described collaborative processes as those in which both families and professionals see each other as actively involved, contributing, and responsible participants in solving problems and reaching decisions. An example of an undesirable decision-making practice was a professional who said, "It's your problem!" to a mother who asked for advice on everyday issues for managing her daughter's behaviors.

Moreover, several participants recommended balanced role-sharing between families and professionals in order to sustain a long-lasting, healthy interdependence. They said families should actively assume whatever roles are reasonable rather than only request professionals to do things for them. They also pointed out that professionals should not take over or dismiss unique roles of family members. They wished that professionals would embrace interdependence and become open to the idea that they could ask families for help. They said they were not often appreciated for what they could offer.

Empathy, Commitment, and Trustworthiness. Many participants spoke of the human qualities they hoped professionals would possess and demonstrate, such as being empathetic, committed, and trustworthy. They talked about how those qualities were crucial in developing a desirable family-professional relationship. One mother spoke especially of empathy as she shared her suspicion that professionals might lose the ability to be empathetic as they acclimated to interacting with families of children with disabilities. Her suspicion stemmed from an encounter with an unsympathetic doctor who disregarded her overwhelming fears related to her son's multiple seizures and said, "Ir's just part of being disabled!"

Professional qualities of empathy and commitment intertwine and increase trust in families. Participants described professionals who were seen as trustworthy allies as follows: "Those professionals do their best," "They do it with all their hearts," and "I can count on them." For example, one mother spoke of a trusting preschool teacher who treated her son with Down syndrome as if he were her own. The mother reflected on the teacher's qualities that earned her deep trust and commented as follows: "I think it is very important for professionals to present trustworthy personalities and human qualities that make us feel that we could comfortably leave our child with this person for an entire day or two."

Last, according to many participants who addressed the issue of good family-professional communication, empathy, commitment, and trust also marked the elements of desirable communication. Moreover, one participant also suggested that open and honest communication would, in turn, nurture the establishment of trusting relationships between families and professionals. 
THEME 4: FAMILY PRIORITIES FOR EMPOWERMENT AND GUIDANCE

Reflecting participants' need for professionals who are empowering guides, this theme had the following subthemes: (a) areas of empowerment, (b) service coordination, and (c) advocacy and mediation.

Areas of Empowerment. Participants expected professionals to excel in their area of training. They expected professionals to tap into their "professional bags" and, through partnerships, empower families and help them gain skills, power, and control to lead the kind of lives they would like to enjoy for themselves and their children. Two main areas emerged in which participants particularly wanted professionals to empower families. The first related to promoting the children's development. This included responsiveness to unique needs arising from the demands of each developmental stage. Some participants also expressed fears of an unknown future (especially what would happen after their children complete school). They suggested that professionals empower families by offering concrete future-related information, such as examples and models of other children and families. They also sought questions that might enable families to start planning their future, as well as empowering information, resources, and skills to help children and families expand possibilities beyond those currently available.

Another issue highlighted by several participants was the effect that disability category labels had on their ability to obtain needed information and guidance. For participants whose child's disability conditions fell into a discrete disability category (e.g., autism, cerebral palsy), relevant information was reportedly helpful, making it easier to access resources geared to their children's conditions and needs. For other participants, however, with children whose disability labels were general or metaphoric (e.g., mental retardation or developmental delay), empowering information and guidance was missing or inaccessible. One participant described her feelings for the past 2 years as "being lost"; she did not know what was needed, or what could be done, to enable her 6 -year-old son to reach the next level. She stated,
"I almost doubt if there is such thing as 'professionals' for us in that sense."

The second area of empowerment was the changing service system. Some participants longed for an empowering advisor, who is knowledgeable of broader topics such as laws and politics. This advisor could teach them to advocate/negotiate and to use effective communication skills. Additionally, this advisor could provide beneficial information such as exemplary practices and models for change, help families organize information/knowledge they acquired, and generate action plans to promote desired service system changes.

\section{Professional qualities of empathy and com- mitment intertwine and increase trust in families.}

Service Coordination. Not only did participants consider the family-professional partnership a dyadic relationship, they also viewed themselves, their children, professionals, and partnerships within the broader context of a complex system involving multiple institutions, disciplines, and layers of organizational and political structures. Eventually, participants advocated for a coordinated team structure and networking system as they pointed out significant shortcomings in the current service system, which was characterized as discontinuous, inconsistent, redundant, fragmented, and disintegrated.

Participants addressed three interrelated aspects to make the service delivery system more coordinated, integrated, and seamless by embracing collaborative teamwork and networking. The first aspect focused on transition, especially from preschool to school-age services. Many participants wished to see better practices for relaying information about the child and the family from sending agencies to receiving agencies. Some also highlighted structural constraints and barriers to information sharing among different agencies (e.g., lack of established procedures or avenues for information sharing), as well as barriers on a personal level (e.g., professionals' low awareness of 
the ongoing nature of the child's development, and the sense of turf and rivalry attitudes among professionals in different fields and agencies).

The second aspect focused on coordinating multiple services often provided by different agencies. Some participants said they needed a main contact person to coordinate services beyond various boundaries so multiple agencies do not disrupt families.

Last, the third aspect of making the services system well-coordinated was to help families locate services, to learn about available services, and to get help when deciding which service to use. One participant repeatedly expressed how she felt lost in the service system maze:

There are so many railroad tracks, and it's us - the parents-who have to decide which track to take. I feel so lost, having no clue which track I should take for my child. I can't see what's there in front. Tunnels everywhere. I could choose one of them by guessing, but then I would have to wonder where does this go and what will the end of this track look like because I can't see anything.

Advocacy and Mediation. Many participants expressed a need for professionals to act as advocates on behalf of children and families. They valued professionals' advocacy resources, including a privileged status that can help amplify families' voices to administrators or policy makers. They also valued professionals' objective views that enable families to be organized and in control, as well as professionals' skills in articulating the rationale of families' request to others. Pointing out that prolonged advocacy might become too much of a burden for families to bear, one participant emphasized the role of professionals as persistent advocates equipped with resources and capabilities necessary for sustainability.

Some addressed the need for a designated place or person to turn to when conflicts arose between families and professionals or the system. One participant said she would like to have a mediator based on her personal difficulty with speaking out and confronting her son's teacher directly. She stated she felt slightly guilty when confronting the teacher because the same teacher took care of her son at school.

\section{DISCUSSION}

\section{FOUR THEMES OF FAMILY-PROFESSIONAL PARTNERSHIPS}

As reported in the previous section, four themes were identified through the data analysis that represented the meaning of family-professional partnerships from participants' perspectives. These four themes are summarized in the following sections.

The first theme focuses on the quality of the child-professional relationship. Participants said that (a) respect should be the foundation of the child-professional relationship; (b) negative and segregative views of disability should be challenged and altered; (c) a child should be understood in the context of developmental history and family and community life (Bronfenbrenner, 1979; Turnbull \& Turnbull, 2001); and (d) educational/developmental services should be planned and implemented based on individually tailored programs, developmentally appropriate practices, meaningful and functional interventions, and practices guided by sound knowledge and trained skills.

The second theme concerns the meaning of professional services and care. Participants said the concept of service was emerging, based on the notion of "right to receive services" and of "consumers' needs" as in the consumer model of the United States (Cunningham \& Davis, 1985). They also addressed the issue of choice, suggesting the importance of promoting a sense of control in the family (Knox, Parmenter, Atkinson, \& Yazbeck, 2000) through planning and providing services and care.

The third theme addresses desired principles of family-professional interactions. Participants said they desired nonhierarchical relationships where equality, reciprocity, interdependence, and collaboration were valued and appreciated by both families and professionals (Blue-Banning et al., 2004; Cunningham \& Davis, 1985; DeChillo et al., 1994; DeChillo, Koren, \& Mezera, 1996; Dunst \& Paget, 1991; Knox et al., 2000; Turnbull et al., 2000; Turnbull \& Turnbull, 2001). They hoped professionals would become families' reliable allies, embodying qualities of empathy, commitment, and trustwor- 
thiness (Blue-Banning et al.; Dinnebeil, Hale, \& Rule, 1996; Dunst \& Paget; Freire, 1970; Knox et al.). Participants also touched upon an emerging notion of "human reciprocity" and of "a moral position collectively recognizing that we each, as human beings, possess a unique value that adds to and strengthens the cultural fabric of society" (Kliewer, 1998, p. 4) in defining the meaning of equality, human values and contributions, and human relationships.

Finally, the fourth theme highlights families' expectations and needs for professionals to empower families and the system through family-professional partnerships and advocacy on behalf of children and their families. This is consistent with the argument that families need to be empowered for a true family-professional partnership to occur (Bond \& Keys, 1993; Turnbull \& Turnbull, 2001). Participants expected that outcomes of family-professional partnerships would empower families and their children, enabling them to lead lives that they choose (Dunst \& Paget, 1991; Knox et al., 2000; Pinderhughes, 1995; Scorgie, Wilgosh, \& McDonald, 1999; Turnbull et al., 2000; Turnbull \& Turnbull). Participants also hoped that partnerships would eventually grow into a collaborative team approach, with networking and well-coordinated service systems (Cunningham \& Davis, 1985; DeChillo et al., 1996; Harrison, Lynch, Rosander, \& Borton, 1990; Park \& Turnbull, 2003).

In subsequent discussions, we refer to those four themes as dimensions of family-professional partnerships because we believe the themes that emerged highlight different dimensions that are part of the constructs of the partnership concept. We are not suggesting that they are definitive or that they are the only dimensions that make up the concept of family-professional partnerships, as they were the only findings of one study with 30 participants. Nonetheless, we believe it is helpful to move from understanding the themes to comprehending and analyzing partnerships in a multidimensional sense. In so doing, we hope to encourage readers to consider the reported themes as pieces of a multidimensional puzzle that can lead to envisioning and shaping a family-professional partnership in practice.

\section{LIMITATIONS OF THE STUDY}

The findings are limited in three ways. First, the data do not include perspectives of key players other than mothers who may be involved in family-professional partnerships, such as other family members and professionals. Second, the sampling procedure, as it was designed, led researchers to recruit only participants who met predetermined selection criteria. Therefore, participants did not fully reflect diverse characteristics of the Japanese population, such as (a) variations in geographicalrelated factors (e.g., a remote village, different cultures of various regions in Japan); (b) personal factors (e.g., age, social-connectedness to others, assertiveness in pursuing better services); (c) family-related factors (e.g., family structure, level of family needs); and (d) child-related factors (e.g., child's age, disability conditions). Finally, this study does not account for broader contextual factors that shape Japanese fields, such as political, economic, societal, and cultural, in which family-professional partnerships are built, interpreted, and negotiated.

\section{CONTRIBUTIONS OF THE STUDY}

Contributions to Japan. In spite of its preliminary nature and limitations of the study, the development of a basis for understanding the meaning of family-professional partnerships is a critical starting point for Japan. Efforts to explore this issue have largely been ignored in Japanese disability-related fields, especially in special education. Furthermore, this study counteracts or questions traditional Japanese notions on a number of issues such as hierarchism in the context of family-professional relationships, which has been accepted and taken for granted historically (Kodama, 1998). The voices of mothers who participated in this study and who called for more equal, nonhierarchical relationships with professionals suggest the need to reexamine and debunk cultural hierarchism in light of professionalism.

This study also reflects emerging forces in Japan that counter traditional meanings of disability that have been based on the medical model and eugenics (Hayashi \&x Okuhira, 2001), and challenges the meaning of care provided for individuals with disabilities, which has been primarily considered the task of one's immediate family 
(Hayashi \& Okuhira; Nakano et al., 1998). As reported in the findings, participants strongly rejected negative and abnormal views of disability and considered disability a part of the normal human condition and of their child's identity. They held society accountable for imposing negative meanings, outlooks, and fates on people with disabilities (Biklen, 1992; Kliewer, 1998; Kunc \& Van der Klift, 1995; Linton, 1998). Participants were active in obtaining and seeking professional services for their children with disabilities based on a belief that they have the right to and are entitled to such support (Cunningham \& Davis, 1985; Hayashi \& Okuhira). They were not discouraged or limited by the traditional notion of "Responsible citizens don't ask others to fulfill the task of taking care of their own family," even though they were still influenced by this notion and occasionally felt guilty for "asking for favors" from society. The medical model of disability as well as hierarchism and "charity of helping" are prevalent in Japan and constitute the foundation of laws, policy, and practices in current Japanese disability fields including special education (Kodama, 1998; Nakano et al.; Yamaguchi \& Kaneko, 2000). Therefore, it is crucial to present alternative perspectives. Such emerging voices should encourage Japanese society, including families of individuals with disabilities and people with disabilities themselves, to reexamine longheld traditional assumptions.

Contributions to the Global Community. Expectations for family-professional partnerships as expressed by the 30 mothers in this study sharply contradicted the value of hierarchy in human relationships in the traditional culture of Japan, as well as of other Asian countries (Kalyanpur \& Harry, 1999; Matsui, 1996; Park \& Turnbull, 2001). This suggests the universal value of a partnership concept in basic human rights issues. Equality is certainly not a universal belief; some cultures value inequality in assigning power based on different backgrounds and characteristics of people, which has been called the "principle of value inequality" (Kalyanpur \& Harry, p. 28). However, such inequality must not be confused with abuse of power. To distinguish it from power abuse, there should be a well-established balance between those with more power and those with less. Those in higher positions should recognize their obligations to protect and ensure the well being of less privileged people (Kalyanpur $\&$ Harry). When the professional power domination is rooted in stigmatizing perceptions of disability and manifests discrimination and inequity, families perceive professionals' interaction as power abuse. Thus, the concept of family-professional partnership can be of value even for families who subscribe to a cultural value of hierarchy if they feel oppressed and need to restore an appropriate power balance with professionals.

Contributions to the United States. This study also adds to current knowledge in the United States where, in spite of the issue's high visibility, a significant gap has been identified regarding the successful operation of family-professional partnerships (Blue-Banning et al., 2004). This study is particularly beneficial and relevant because it highlights emerging dimensions of family-professional partnerships (i.e., the four themes). Knowing what dimensions and aspects of human relationship are crucial in determining the basic nature, qualities, and operation of family-professional partnership should facilitate establishing desirable partnership (Blue-Banning et al.; Musgrave \& Anniss, 1996).

The qualitative and inductive methodology in this study encouraged researchers not to assume that partnership is defined only in terms of interpersonal relationships, nor to limit the scope of discussion issues strictly to dyadic working relationships between families and professionals. This approach enabled researchers to understand the meaning of partnership more holistically. This study suggests that defining the meaning of a family-professional partnership involves not only the question of "How would you like to work, interact, and communicate with your partner?", but also involves questions that help partners clarify their own views of a child, disability, quality of life, care and support, human reciprocity, power and control, society and system, and personal/shared/societal goals. Such a holistic understanding and discussion of family-professional partnerships offer a new direction to the current research and practice in family-professional partnerships (Blue-Banning et al., 2004). 


\section{IMPLICATIONS FOR FUTURE RESEARCH}

Potential research questions for further inquiries may include:

- What are the perspectives of various stakeholders such as different family members and professionals?

- Are there significant differences regarding perspectives and expectations toward family-professional partnerships (a) between families and professionals; (b) among families who differ in geographical, personal, family-related, childrelated, and any other factors that might affect perceptions of such partnerships; and (c) among different types of professionals who work in different fields (e.g., special/general teachers, therapists, doctors, administrators, social workers, community nurses, etc.)?

- What kind of social, cultural, economic, political, systemic, and/or academic factors affect attitudes and expectations toward family-professional partnerships (e.g., national/international policies on education, special education, disability-related services, economics; legislation and regulations; conception of disability; the disability rights movement; research trends; national movements such as feminism that may affect cultural trends)?

- How can those various perspectives and contextual factors inform our conceptual understanding of family-professional partnerships and expand/modify/alter the dimensions that emerged in this study to elucidate the essence of the family-professional partnership concept?

IMPLICATIONS FOR BUILDING

PARTNERSHIPS WITH CULTURALLY

DIVERSE FAMILIES

The concluding discussion in this article focuses on the issue of developing partnerships with culturally diverse families. Previously, we suggested that the partnership concept might have some universal values applicable to families and professionals in different cultures. However, it absolutely does not suggest there is a universal pattern in family-professional partnerships. Rather, partnerships can and should look different in different situations according to what partners desire in each dimension of their partnership. Cultural differences, such as those reflected in parenting practices (Kalyanpur \& Harry, 1999) and values in independence (Turnbull \& Turnbull, 2001), contribute to unique characteristics in each partnership. Professionals must respect each family's culture and understand the cultural values that may underlie the family's particular style of working with them.

Professionals also should try to ensure that the partnership is based on families' fully informed decisions that reflect their personal as well as cultural values (Kalyanpur \& Harry, 1999). A key consideration is that a family may seem to be satisfied with, or even prefer, a more traditional hierarchical relationship with professionals. For example, participants in this study never spoke of families' roles or contributions as equal to those of professionals in the assessment process. However, this perspective may not reflect a desire to be excluded, but rather may reflect traditional assumptions that value scientific knowledge and devalue the family's knowledge of everyday experiences (Kalyanpur \& Harry). Thus, professionals need to assure (a) that families are fully aware of all available options and models for family-professional partnership (Turnbull et al., 2000); (b) that they have necessary knowledge and skills to actualize the family-professional partnership they prefer (Park, Turnbull, \& Park, 2001); and (c) that they have enough opportunities to participate in the partnership (Turnbull \& Turnbull, 2001).

Learning about and respecting a family's culture is essential. However, knowing which ethnic group a family belongs to or pursuing how-to information for each culture is not the key to forming a family-professional partnership with culturally diverse families. Respecting culture begins with efforts to know each individual family (Kalyanpur \& Harry, 1999). The authors suggest inductive thinking and dialogue (Freire, 1970) as a key for professionals to genuinely understand a "family's reality" (Kalyanpur \& Harry, p. 87) and the unique culture of each family. An inductive approach enables professionals to avoid the deductive thinking of fitting the family into a cultural mold. It encourages professionals to listen to each family and learn specific meanings and elements of partnership that the family desires, based on their own reality and unique application 
of traditional culture in their daily lives.

The dimensions of family-professional partnerships that emerged in this study offer a guide to inductive dialogue of searching for the unique meaning of each family-professional partnership. Through such an inductive dialogue, potentials of diverse partnership patterns become endless and each partnership shall begin to take on a distinctive form, outlook, and atmosphere that together represent unique identities of those involved.

\section{REFERENCES}

Allen, R. I., \& Petr, C. G. (1996). Toward developing standards and measurements for family-centered practice in family support programs. In G. H. S. Singer, L. E. Powers, \& A. L. Olson (Eds.), Redefining family support: Innovations in public-private partnerships (pp. 5786). Baltimore: Brookes.

Blue-Banning, M., Summers, J. A., Frankland, H. C., Nelson, L. L., \& Beegle, G. (2004). Dimensions of family and professional partnerships: Constructive guidelines for collaboration. Exceptional Children, 70, 167-184.

Biklen, D. (1992). Schooling without labels: Parents, educators, and inclusive education. Philadelphia: Temple University Press.

Bogdan, R. C., \& Biklen, S. K. (2003). Qualitative research for education: An introduction to theory and methods (4th ed.). Boston: Allyn \& Bacon.

Bond, M., \& Keys, C. (1993). Empowerment, diversity, and collaboration: Promoting synergy on community boards. American Journal of Community Psychology, 21, 37-57.

Bronfenbrenner, U. (1979). The ecology of human development: Experiments by nature and design. Cambridge, MA: Harvard University Press.

Brotherson, M. J. (1994). Interactive focus group interviewing: A qualitative research method in early intervention. Topics in Early Childhood Special Education, 14, 101-118.

Cunningham, C., \& Davis, H. (1985). Working with parents: Frameworks for collaboration. Philadelphia: Open University Press.

DeChillo, N., Koren, P. E., \& Mezera, M. (1996). Families and professionals in partnership. In B. A. Stroul (Ed.), Children's mental health: Creating systems of care in a changing society (pp. 389-407). Baltimore: Brookes.
DeChillo, N., Koren, P. E., \& Schultze, K. H. (1994). From paternalism to partnership: Family and professional collaboration in children's mental health. American Journal of Orthopsychiatry, 64, 564-576.

Dinnebeil, L. A., Hale, L. M., \& Rule, S. (1996). A qualitative analysis of parents' and service coordinators' description of variables that influence collaborative relationships. Topics in Early Childhood Special Education, 16, 322-347.

Dunst, C. J., \& Paget, K. D. (1991). Parent-professional partnerships and family empowerment. In M. J. Fine (Ed.), Collaboration with parents of exceptional children (pp. 25-44). Brandon, VT: Clinical Psychology Publishing Company.

Freire, P. (1970). Pedagogy of the oppressed. New York: Herder and Herder.

Harrison, P. J., Lynch, E. W., Rosander, K., \& Borton, W. (1990). Determining success in interagency collaboration: An evaluation of processes and behaviors. Infants and Young Children, 3, 69-78.

Hayashi, R., \& Okuhira, M. (2001). The disability rights movement in Japan: Past, present, and future. Disability and Society, 16, 855-869.

Kalyanpur, M., \& Harry, B. (1999). Culture in special education: Building reciprocal family-professional relationships. Baltimore: Brookes.

Kliewer, C. (1998). Schooling children with Down syndrome: Toward an understanding of possibility. New York: Teachers College Press.

Knox, M., Parmenter, T. R., Atkinson, N., \& Yazbeck, M. (2000). Family control: The views of families who have a child with an intellectual disability. Journal of Applied Research in Intellectual Disabilities, 13, 17-28.

Kodama, M. (1998). Watashi-wa-watashirashiishougaiji-no-hahadeii [Being a mother of a child with disabilities in my own way]. Tokyo, Japan: Budou-sha.

Krueger, R. A., \& Casey, M. A. (2000). Focus groups: A practical guide for applied research (3rd ed.). Thousand Oaks, CA: Sage .

Kunc, N., \& Van der Klift, E. (1995). In spite of my disability. Retrieved March 14, 2002, from http://www.normemma.com/arinspit.htm

Lincoln, Y. S., \& Guba, E. G. (1985). Naturalistic inquiry. Thousand Oaks, CA: Sage.

Linton, S. (1998). Claiming disability: Knowledge and identity. New York: New York University Press.

Matsui, W. T. (1996). Japanese families. In M. McGoldrick, J. Glordano, \& J. K. Pearce (Eds.), Ethnicity and family therapy (2nd ed., pp. 268-280). New York: Guilford. 
Miles, M. B., \& Huberman, A. M. (1994). Qualitative data analysis: An expanded sourcebook (2nd ed.). Thousand Oaks, CA: Sage.

Ministry of Education, Culture, Sport, Science, and Technology Japan. (2001). 21seiki-no-tokusyukyouiku-noarikata-ni-tuite: Hitoribitori-no-nizu-ni-oujitatokubetu-nasien-no-arikata-ni-tuite /Final report on special education in the $21^{\text {st }}$ century: Framework of special support provision based on individual needs]. Retrieved October 15, 2001, from http://www.mext.go.jp/b_menu/shingi/ chousa/shotou/006/toushin/010102.htm

Ministry of Education, Culture, Sport, Science, and Technology Japan. (2003). Kongo-no-tokubetsu-sien-kyoiku-no-arikata-ni-tsuite [Final report on the direction of the special needs education in the next era]. Retrieved April 11, 2003, from http://www.mext.go.jp/ b_menu/shingi/chousa/shotou/018/toushin/030301.htm

Ministry of Health, Labour, and Welfare of Japan. (1998). Syakaihukusikisokouzoukeikaku-ni-tuite: Chukanmatome-no-youten [A preliminary report on restructuring plan of the fundamental social welfare system framework]. Retrieved January 26, 2001, from http://wwwl.mhlw.go.jp/houdou/1006/h0617-1.html

Musgrave, J., \& Anniss, M. (1996). Relationships $d y$ namics: Theory and analysis. New York: The Free Press.

Nakano, T., Tazawa, A., Kaneko, T., Nakatosi, T., Iwasaki, S., Takizawa, K., et al. (Eds.). (1998). Riyosyasyutai-no-kazokuenzyo: Syougaiji-to-kazoku-nokurashi-wo-kangaeru [Consumer-centered family support: Support lives of children with disabilities and their families.] Chiba, Japan: Taiyo-sya.

Park, J., \& Turnbull, A. P. (2001). Cross-cultural competency and special education: Perceptions and experiences of Korean parents of children with special needs. Education and Training in Mental Retardation and Developmental Disabilities, 36, 133-147.

Park, J., \& Turnbull, A. P. (2003). Service integration in early intervention: Determining interpersonal and structural factors for its success. Infants and Young Children, 16, 48-58.

Park, J., Turnbull, A. P., \& Park, H. S. (2001). Quality of partnerships in service provision for Korean American parents of children with disabilities: A qualitative inquiry. Journal of the Associations for Persons with Severe Handicaps, 26, 158-170.

Pinderhughes, E. (1995). Empowering diverse populations: Family practice in the 21 st century. Families in society: The Journal of Contemporary Human Services, (CEU article no. 50), 131-140.

Scorgie, K., Wilgosh, L., \& McDonald, L. (1999). Transforming partnerships: Parent life management issues when a child has mental retardation. Education and Training in Mental Retardation and Developmental Disabilities, 34, 395-405.

Skrtic, T. M. (1985). Doing naturalistic research into educational organizations. In Y. S. Lincoln (Ed.), Organizational theory and inquiry: The paradigm revolution (pp. 185-220). Beverly Hills, CA: Sage.

Turnbull, A. P., Turbiville, V., \& Turnbull, H. R. (2000). Evolution of family-professional partnerships: Collective empowerment as the model for the early twenty-first century. In J. P. Shonkoff \& S. J. Meisels (Eds.), Handbook of early childhood intervention (2nd ed., pp. 630-650). New York: Cambridge University Press.

Turnbull, A. P., \& Turnbull, H. R. (2001). Families, professionals, and exceptionality: Collaborating for empowerment (4th ed.). Upper Saddle River, NJ: Merrill/Prentice-Hall.

Yamaguchi, K., \& Kaneko, T. (2000). Tokusyukyoikuno-tenbou: Syougaiji-kyouiku-kara-tokubetsu-sien-kyouiku-he [Current trends in special education: From education of disabled students to the special needs education]. Tokyo, Japan: Nihon-bunka-kagaku-sya.

\section{ABOUT THE AUTHORS}

maho Kasahara, Doctoral Student, School of Education, Special Education/Disability Studies, Syracuse University, New York. AN N P. Turngull, Co-director, Beach Center on Disabilities, University of Kansas, Lawrence.

Correspondence concerning this article should be addressed to Maho Kasahara, 370 Huntington Hall, Syracuse, NY 13244-2340. Phone: 315443-0280 (e-mail: mkasahar@syr.edu)

Manuscript received October 2003; accepted May 2004. 
Copyright of Exceptional Children is the property of Council for Exceptional Children. The copyright in an individual article may be maintained by the author in certain cases. Content may not be copied or emailed to multiple sites or posted to a listserv without the copyright holder's express written permission. However, users may print, download, or email articles for individual use. 